\title{
EL ABOGADO LABORALISTA ANTE LA CUESTIÓN PREJUDICIAL EUROPEA
}

\author{
JESÚS MARTÍNEZ GIRÓN \\ ALBERTO ARUFE VARELA \\ Catedrático de Derecho del Trabajo \\ Catedrático acreditado de Derecho del Trabajo \\ Universidad de A Coruña
}

Resumen: Sobre la base de que lo que precede al planteamiento de la cuestión prejudicial europea carece de regulación en nuestro Derecho positivo, este trabajo analiza la posición del abogado laboralista postulando u oponiéndose a que el juez cree su convicción de que dicha cuestión hay que plantearla. Se trata de un estudio realizado sobre una muestra significativa de resoluciones judiciales laborales, cuyo análisis acredita la existencia de muy diversos problemas procesales, que el legislador español ha renunciado de momento a resolver. El trabajo propugna una nueva reforma de la Ley orgánica del poder judicial, que profundice en la ya realizada por la Ley orgánica $7 / 2015$.

Palabras clave: abogado laboralista; cuestión prejudicial europea; partes procesales, procesos laborales; Unión Europea

Resumo: Sobre a base de que o que precede á formulación da cuestión prexudicial europea carece de regulación no noso Dereito positivo, este traballo analiza a posición do avogado laboralista postulando ou opóndose a que o xuíz cre a súa convicción de que dita cuestión hai que expola. Trátase dun estudo realizado sobre unha mostra significativa de resolucións xudiciais laborais, cuxo análise acredita a existencia de moi diversos problemas procesuais, que o lexislador español renunciou de momento a resolver. O traballo propugna unha nova reforma da Lei orgánica do poder xudicial, que profunde na xa realizada pola Lei orgánica 7/2015. 
Palabras chave: avogado laboralista; cuestión prexudicial europea; partes procesuais; procesos laborais; Unión Europea

Sumario: I. LAS FUENTES REGULADORAS.- II. EL NATURAL ESCEPTICISMO DEL JUEZ LABORAL.- III. LA POSICIÓN DEL ABOGADO LABORALISTA DEL DEMANDANTE.- IV. LA POSICIÓN DEL ABOGADO LABORALISTA DEL DEMANDADO.- V. EPÍLOGO.

\section{LAS FUENTES REGULADORAS ${ }^{1}$}

1. Quizá lo primero a tener en cuenta por un abogado laboralista es que el tema de la cuestión prejudicial europea no aparece tratado, ni siquiera mencionado, en la Ley de ritos procesales laborales - sin duda, la norma referente para dicha concreta especie de abogado- - esto es, la Ley 36/2011, reguladora de la jurisdicción social. En realidad, en cuanto a esto, no ha habido novedad que pueda sorprendernos a nosotros, los laboralistas, pues tampoco aludía a dicho tema nuestra séptima y última Ley de procedimiento laboral de $1995^{2}$, que inmediatamente precedió a la actualmente vigente, y que fue derogada por ella. Desde un punto de vista europeísta, hay que tener en cuenta, sin embargo, que ambas Leyes no son en absoluto normas clónicas. En efecto, la Ley de 1995 callaba totalmente sobre el Derecho comunitario (y lo mismo ocurría con nuestra sexta Ley de Procedimiento Laboral de 1990) ${ }^{3}$. Sin embargo, la Ley 36/2011 ha comenzado a invertir esa tradicional tendencia «negacionista» de lo europeo en el ámbito de los ritos procesales, al afirmar ahora - a propósito del recurso de casación para la unificación de doctrina - no sólo que «podrá alegarse como doctrina de contradicción la establecida en las sentencias dictadas por el Tribunal Constitucional y los órganos jurisdiccionales instituidos en los Tratados y Acuerdos internacionales en materia de derechos humanos y libertades fundamentales ratificados por España» ${ }^{4}$, sino también que «con iguales requisitos y alcance sobre su aplicabilidad, podrá invocarse la doctrina establecida en las sentencias del Tribunal de Justicia de la Unión Europea en interpretación del derecho comunitario» ${ }^{5}$.

2. En esto de omitir mencionar la cuestión prejudicial europea, muestra Ley 36/2011 estuvo acompañada durante casi un cuatrienio por la Ley orgánica 6/1985, de 1 julio, del poder judicial, que igualmente silenciaba su existencia. Pero este estado de cosas cambia al enmendarse la segunda por la Ley orgánica 7/2015, de 21 julio. En efecto, la

\footnotetext{
${ }^{1}$ Trabajo realizado al amparo del proyecto de investigación estatal DER2016-75741-P, otorgado por el Ministerio de Economía, Industria y Competitividad. Fue defendido en el seminario sobre «La jurisprudencia del Tribunal de Justicia de la Unión Europea en materia laboral y social», celebrado el día 24 de marzo de 2017, en la Facultad de Derecho de la Universidad Complutense de Madrid.

${ }^{2}$ Texto refundido aprobado por Real Decreto Legislativo 2/1995, de 7 abril. Sobre la serie histórica de nuestras leyes procesales laborales, véase J. MARTÍNEZ GIRÓN, A. ARUFE VARELA y X.M. CARRIL VÁZQUEZ, Derecho del Trabajo, $2^{\mathrm{a}}$ ed., Netbiblo (A Coruña, 2006) págs. 75 y ss.

${ }^{3}$ Texto articulado aprobado por Real Decreto Legislativo 521/1990, de 27 abril.

${ }_{5}^{4}$ Artículo 219, apartado 2, párrafo primero.

${ }^{5}$ Ibidem, párrafo segundo.
} 
norma enmendante - después de reconocer, en su preámbulo, que «resulta conveniente mencionar en la Ley la vinculación de los Jueces y Tribunales españoles al Derecho de la Unión, en la interpretación que hace del mismo el Tribunal de Justicia de la Unión Europea» ${ }^{6}$, por lo que «en paralelo, y como corolario del sistema, se determina la forma en la que en nuestro ordenamiento ha de plantearse procesalmente el principal cauce de diálogo entre el Juez español y el Tribunal de Justicia de la Unión Europea: la cuestión prejudicial» — procedió a añadir a la Ley orgánica 6/1985 un nuevo artículo 4bis ${ }^{8}$, cuyo apartado 2 no dice, en realidad, nada que ya no supiésemos, pues lo nuevo — sólo supuestamente - que establece es lo siguiente. En primer, el que haya procedido a bautizar la cuestión prejudicial, llamándola expresamente cuestión prejudicial «europea», quizá con el propósito de distinguirla de otras muchísimas cuestiones prejudiciales de que tradicionalmente venían conociendo nuestros tribunales (y así, por ejemplo, las cuestiones prejudiciales civiles, contencioso-administrativas o penales, que resolvían, literalmente desde el año de la polka, nuestros tribunales laborales) ${ }^{9}$. En segundo lugar, supuesto que los tribunales de todos los órdenes decidan plantearla, el que «lo harán de conformidad con la jurisprudencia del Tribunal de Justicia de la Unión Europea y, en todo caso, mediante auto, previa audiencia de las partes».

3. Como se ve, un precepto equivalente en la práctica a no decir nada, pues lo que manda hacer ya se venía haciendo. Y se hacía, también por parte de nuestros tribunales laborales, teniendo que saltar y sortear multitud de vallas y obstáculos suscitados por la práctica forense, que en absoluto refleja ese nuevo y telegráfico precepto de nuestra Ley orgánico-procesal por antonomasia. Ahora bien, dicha problemática jurídico-procesal que es previa al planteamiento de la cuestión prejudicial europea- sí aparece registrada en una casuística judicial, que nos hemos animado a sistematizar y a estudiar, y que expondremos aquí en sus trazos más estructurales. Al respecto, hemos considerado significativas dieciocho Sentencias, de las que nueve son de la Sala de lo Social del Tribunal Supremo ${ }^{10}$, y las restantes de Salas de lo Social de diversos Tribunales Superiores de Justicia, actuando como tribunales de suplicación ${ }^{11}$. De entre las nueve

\footnotetext{
${ }^{6}$ Cfr. apartado VI, párrafo segundo, inciso primero.

${ }^{7}$ Ibidem, inciso segundo. Sobre dicho «diálogo», véase R. ALONSO GARCÍA, «La cuestión prejudicial, piedra angular de la integración europea», en R. ALONSO GARCÍA y J.I. UGARTEMENDIA ECEIZABARRENA (Directores), La cuestión prejudicial europea, IVAP (Oñati, 2014), págs. 9 y ss.

${ }^{8}$ Cfr. su artículo único, apartado dos.

${ }^{9}$ En la Ley 36/2011, véanse sus artículos 4, 86 y 260.

${ }^{10}$ Sentencia de 27 marzo 1995 (Aranzadi Westlaw, referencia RJ 1995/2560), Sentencia de 17 noviembre 1995 (Aranzadi Westlaw, referencia RJ 1995/9302), Sentencia de 12 febrero 1997 (Aranzadi Westlaw, referencia RJ 1997/1259), Sentencia de 24 junio 2009 (Aranzadi Westlaw, referencia RJ 2009/4286), Sentencia de 11 julio 2012 (Aranzadi Westlaw, referencia RJ 2012/9969), Sentencia de 25 octubre 2013 (Aranzadi Westlaw, referencia RJ 2013/7749), Sentencia de 6 febrero 2014 (Aranzadi Westlaw, referencia RJ 2014/944), Sentencia de 16 septiembre 2014 (Aranzadi Westlaw, referencia RJ 2014/5040) y Sentencia de 17 septiembre 2014 (Aranzadi Westlaw, referencia RJ 2014/5555).

${ }^{11}$ Sentencia de la Sala de lo Social de Sevilla del Tribunal Superior de Justicia de Andalucía de 30 noviembre 1992 (Aranzadi Westlaw, referencia AS 1992/6595), Sentencia de la Sala de lo Social del Tribunal Superior de Justicia de la Comunidad Valenciana de 15 junio 1993 (Aranzadi Westlaw, referencia AS 1993/3069), Sentencia de la Sala de lo Social del Tribunal Superior de Justicia de Galicia de 27 octubre 1993 (Aranzadi Westlaw, referencia AS 1993/4252), Sentencia de la Sala de lo Social del Tribunal Superior de Justicia de Cataluña de 16 febrero 1994 (Aranzadi Westlaw, referencia AS 1994/577), Sentencia de la Sala de lo Social del Tribunal Superior de Justicia de Cataluña de 14 junio 1994 (Aranzadi Westlaw, referencia AS 1994/2563), Sentencia de la Sala de lo Social del Tribunal Superior de Justicia de Cantabria de 14 abril 2008 (Aranzadi Westlaw, referencia AS 2008/1703), Sentencia de la Sala de lo Social del Tribunal Superior de Justicia de Madrid de 17 julio 2009 (Aranzadi Westlaw, referencia AS 2009/114), Sentencia de la Sala de lo Social del Tribunal Superior de Justicia de
} 
del Tribunal Supremo, destacamos tres, por haber sido dictadas por su Sala de lo Social actuando en pleno $^{12}$. Y de entre estas tres, consideramos que merece ser especialmente destacada una, sobre la que volveremos con más detalle luego (pensamos, incluso, que debería ser una Sentencia de lectura obligada en todas las Facultades de Derecho), pues lo frontalmente debatido en ella por el pleno de la Sala, con discordia en su seno, fue si debería o no plantarse cuestión prejudicial europea, con argumentos a favor y en contra (esgrimidos por Magistrados con personalidades muy acusadas y perfiles muy distintos, en concepto de ponente de la mayoría y de líder de la minoría discrepante), trabados en un debate de gran altura sobre lo que debía o no considerarse como «certidumbre» del Derecho $^{13}$.

\section{EL NATURAL ESCEPTICISMO DEL JUEZ LABORAL}

4. El escenario descrito por esa muestra significativa de dieciocho Sentencias laborales es diáfano, y está marcado por la presencia en escena de un juez laboral escéptico. Y escéptico, por un cúmulo de razones, que son a la vez fácticas (o si se quiere, culturales en sentido amplio) y jurídicas. Ante todo, la de que el juez — culturalmente hablandono duda, porque si lo hace y se niega a fallar, comete entonces delito de prevaricación (literalmente, «el Juez o Magistrado que se negase a juzgar, sin alegar causa legal, o so pretexto de oscuridad, insuficiencia o silencio de la Ley, será castigado con la pena de inhabilitación especial para empleo o cargo público por tiempo de seis meses a cuatro años») ${ }^{14}$, aunque aquí, en materia de planteamiento de la cuestión prejudicial europea, sí que le esté permitido dudar y, en consecuencia - aunque temporalmente-, negarse a juzgar. Además, hay que tener en cuenta que el juez laboral es un funcionario, sometido a una carga de trabajo - medida incluso por «módulos de rendimiento»- muy pesada, y con todas las inercias y rutinas que en general nos caracterizan a nosotros, los funcionarios. Y plantear cuestión prejudicial es salirse de los protocolos judiciales de actuación habituales u ordinarios, supuesto que el juez que se animase a tramitarla se auto-endosaría trabajo adicional, caracterizado por el hecho de que todo tendría que hacerlo él (esto es, leer las normas comunitarias reguladoras del asunto, poner por escrito sus dudas y, por supuesto, redactar el «auto» de que habla ahora la Ley orgánica del poder judicial, «previa audiencia de las partes», suspendiendo la tramitación del asunto laboral en curso, y a la espera de que llegue la respuesta del Tribunal de Justicia de la Unión Europea, eventualmente larga y prolija, que también tendrá luego que estudiarse).

5. En relación con esto último, hemos comprobado que también aquí - como en tantos otros ámbitos - puede llegar a ser peor el remedio que la enfermedad. Lo acredita contundentemente una Sentencia de la Sala de lo Social del Tribunal Superior de Justicia de Cataluña de 16 febrero $1994^{15}$, relativa a qué podría llegar a suceder cuando

Madrid de 24 octubre 2014 (Aranzadi Westlaw, referencia AS 2014/2643) y Sentencia de la Sala de lo Social del Tribunal Superior de Justicia de Madrid de 12 diciembre 2015 (Aranzadi Westlaw, referencia AS 2015/297).

${ }^{12}$ Sentencia de 17 noviembre 1995 (Aranzadi Westlaw, referencia RJ 1995/9302), Sentencia de 24 junio 2009 (Aranzadi Westlaw, referencia RJ 2009/4286) y Sentencia de 11 julio 2012 (Aranzadi Westlaw, referencia RJ 2012/9969).

${ }^{13}$ Véase infra, núm. 12.

${ }^{14}$ Artículo 448 del Código Penal.

${ }^{15}$ Citada supra, núm. 3.. 
llegase la respuesta del Tribunal de Luxemburgo a las cuestiones planteadas a él por lo propia Sala. Estos sucesos los relata el voto particular contenido en dicha Sentencia, redactado por el Magistrado Sr. Odón MARZAL MARTÍNEZ. En este interesantísimo escrito, se afirma todo lo siguiente: 1) «el Tribunal de Luxemburgo no ha resuelto ... ni el responsable u obligado que en concreto debe atender las consecuencias de dicho impago (cuestión principal que en definitiva provoca este voto particular), ni tampoco, caso de ser el Estado y no el FGS, el Orden de la Jurisdicción competente, ante el que puede instarse la protección actualmente negada, ni por fin, caso de ser la competencia del orden laboral, el tipo de procedimiento o modalidad procesal que resulte la adecuada o correcta para ello» ${ }^{16}$; 2) «para mayor complicación debe resaltarse ya, que durante la suspensión acordada en este proceso ... como consecuencia del planteamiento de la Cuestión Prejudicial, el TS ha dictado en 30 diciembre 1992 una Sentencia en unificación de doctrina» ${ }^{17}$, cuyos «argumentos no dejan de sorprender» ${ }^{18}$, pues, «obviamente no han dicho lo mismo ambos máximos Tribunales Judiciales, el español y el comunitario» ${ }^{19}$; y 3) aparentemente, el Tribunal de Luxemburgo en su respuesta cometió un «error», dada la «analogía fonética en lenguaje hispano, pero de profunda diferencia real entre regulación actual y creación», derivado del hecho de que «el Tribunal ni entra, por cuanto no es su misión, ni conoce a fondo el derecho español» ${ }^{20}$. Sólo le faltó confesar al redactor de este voto particular que el verdadero error fue, en realidad, el planteamiento de cuestión prejudicial por parte de la Sala de lo Social catalana; y más, teniendo en cuenta — según él— que «otros miembros de esta propia Sala, sin esperar tampoco a conocer la solución a la referida Cuestión Prejudicial por el Tribunal de Justicia de Luxemburgo han dictado, otra Sentencia en 2 diciembre 1993, siguiendo la doctrina anteriormente citada en la Sentencia del Tribunal Supremo de 30 diciembre 1992» ${ }^{21}$.

6. Evidentemente, este tipo de resultas contribuye a alimentar el escepticismo judicial a que venimos aludiendo. Y debe haber mucho juez escéptico en toda la Unión Europea, pues el Tribunal de Luxemburgo — de acuerdo con sus propias estadísticas oficialesviene resolviendo por Sentencia una media de 300 cuestiones prejudiciales al año (más en concreto, 296 en 2015, y 302 en 2016) ${ }^{22}$, lo que supone una carga de trabajo a calificar de liviana (similar a la que soporta, al resolver «certioraris», la Corte Suprema de los Estados Unidos) ${ }^{23}$. Hay que tener en cuenta, además, que en esos tres centenares de Sentencias se incluyen aquellos supuestos de hecho en los que el Tribunal de Luxemburgo admite a trámite la cuestión prejudicial, sí, aunque luego se declara incompetente para resolverla - lo que supone un duro golpe a la motivación del juez nacional, supuesto que llegase a animarse a volver a plantear otra más tarde-, como ocurrió en el asunto resuelto por la Sentencia del Tribunal de Justicia de la Unión

\footnotetext{
${ }^{16} \mathrm{Cfr}$. razón $1^{\mathrm{a}}$, párrafo segundo, inciso primero.

${ }^{17} \mathrm{Cfr}$. razón $2^{\mathrm{a}}$, inciso segundo.

${ }^{18}$ Ibidem, inciso tercero.

${ }^{19}$ Ibidem, inciso cuarto.

${ }^{20} \mathrm{Cfr}$. razón $7^{\mathrm{a}}$

${ }^{21}$ Cfr. razón $2^{a}$, inciso quinto.

${ }^{22}$ Véase Court of Justice of the European Union. Annual report 2016. Judicial activity, localizable en www.curia.europa.eu, pág. 209.

${ }^{23}$ Nuestra visión sobre este peculiar «recurso», en J. MARTÍNEZ GIRÓN, Quince grandes casos de la Corte Suprema de los Estados Unidos sobre Derecho individual del Trabajo. Un estudio desde la perspectiva del Derecho español, Netbiblo (A Coruña, 2012), págs. 2 y ss.; y A. ARUFE VARELA, El Derecho de la Seguridad Social en la jurisprudencia de la Corte Suprema de los Estados Unidos. Un estudio de veintisiete grandes casos, desde la perspectiva del Derecho español, Atelier (Barcelona, 2014), págs. 33 y ss.
} 
Europea de 5 febrero $2015^{24}$, relativa a lo siguiente: 1) «[la] petición de decisión prejudicial [fue] planteada, con arreglo al artículo 267 TFUE, por el Juzgado de lo Social núm. 23 de Madrid, mediante resolución de 4 de marzo de $2014{ }^{25}$; 2) «según el órgano jurisdiccional remitente, el [período de prueba de un año en el] contrato de trabajo por tiempo indefinido de apoyo a los emprendedores infringe el artículo 30 de la Carta [de los Derechos Fundamentales de la Unión Europea], los artículos 2.2, letra b), y 4 del Convenio $\mathrm{n}^{\mathrm{o}} 158$ sobre la terminación de la relación de trabajo, adoptado el 22 de junio de 1982, en Ginebra, por la Organización Internacional del Trabajo, la Carta Social Europea, firmada en Turín el 18 de octubre de 1961 —infracción que resulta del contenido de una decisión de 23 de mayo de 2012 del Comité Europeo de Derechos Sociales relativa a un contrato griego similar-, y la Directiva 1999/70» ${ }^{26}$; y 3) sin embargo, «del conjunto de las anteriores consideraciones resulta que la situación analizada en el litigio principal no se encuentra comprendida en el ámbito de aplicación del Derecho de la Unión» ${ }^{27}$, de manera que, al modo de un verdadero mazazo dado a dicho Juez de lo Social madrileño, se impuso la conclusión de que «por consiguiente, el Tribunal de Justicia no es competente para responder a las cuestiones planteadas por el órgano jurisdiccional remitente» ${ }^{28}$.

\section{LA POSICIÓN DEL ABOGADO LABORALISTA DEL DEMANDANTE}

7. Como se sabe, en los procesos laborales, la regla general es que el demandante sea un trabajador o un beneficiario de prestaciones de seguridad social ${ }^{29}$, lo que obliga a concluir — siempre a título de regla — que su abogado será el típico abogado de trabajadores (incluido aquí el típico abogado sindicalista), en cuanto que opuesto al típico abogado laboralista que sólo «lleva» empresas. La casuística resuelta por el Tribunal de Luxemburgo refleja que puede ser el típico abogado laboralista modesto, de los que tantos y tantos hay en provincias, que defiende a sus clientes asimismo modestos (por ejemplo, una limpiadora de portales, que trabajaba a tiempo parcial, y a quien el INSS denegó su pensión de jubilación) ${ }^{30}$, resultando evidente que este tipo de pleitos laborales, aunque clamorosamente «modestos»-por ejemplo, desde la perspectiva de todos esos grandes bufetes, en que trabajan muchos de nuestros colegas catedráticos, con sus característicos «clientes sofisticados» ${ }^{31}$-, pueden llegar a hacer tambalear los presupuestos del Estado y, por supuesto, también los presupuestos de la seguridad social. Lógicamente, lo que pretende ese abogado es bien sencillo. Invocando el Derecho de la Unión Europea, bien originario, bien derivado, trata de sembrar la duda

\footnotetext{
${ }^{24}$ En el asunto C-117/14, caso Grima Janet Nisttahuz Poclava contra José María Ariza Toledano.

${ }^{25} \mathrm{Cfr}$. su encabezamiento.

${ }^{26}$ Marginal 23.

${ }^{27}$ Marginal 44, inciso primero.

${ }^{28}$ Ibidem, inciso segundo.

${ }^{29}$ Al respecto, véase J. MARTÍNEZ GIRÓN y A. ARUFE VARELA, Derecho crítico del Trabajo. Critical Labor Law, $4^{\mathrm{a}}$ ed., Atelier (Barcelona, 2016), págs. 254-255.

${ }^{30}$ Al respecto, véase la cuestión prejudicial resuelta por Sentencia del Tribunal de Justicia de la Unión Europea de 22 noviembre 2012, en el asunto C-385/11. Sobre el tema, J. MARTÍNEZ GIRÓN, A. ARUFE VARELA y X.M. CARRIL VÁZQUEZ, Derecho de la Seguridad Social, 4a ed., Atelier (Barcelona, 2017), págs. 78-79.

${ }^{31}$ Tomamos la expresión de un famoso dictum del Juez Antonin SCALIA de la Corte Suprema de los Estados Unidos. Sobre él, véase A. ARUFE VARELA, El Derecho de la Seguridad Social en la jurisprudencia de la Corte Suprema de los Estados Unidos. Un estudio de veintisiete grandes casos, desde la perspectiva del Derecho español, cit., págs. 119-120.
} 
sobre el resultado del pleito, con la finalidad de crear en el tribunal laboral la convicción de que debe animarse a plantear la cuestión prejudicial europea. La «duda» sobre la interpretación o sobre la aplicabilidad en el pleito del Derecho comunitario resulta clave. Y así lo ponen de relieve las utilísimas «Recomendaciones a los órganos jurisdiccionales nacionales, relativas al planteamiento de cuestiones prejudiciales», publicadas en el Diario Oficial de la Unión Europea, ${ }^{32}$ donde se adjetiva incluso la palabra crucial en cuestión, al hablar de «dudas reales» ${ }^{33}$ y de «serias dudas» ${ }^{34}$, aunque baste simplemente —como también afirman las propias «Recomendaciones»— con que el órgano jurisdiccional nacional proponente de la cuestión «albergue dudas» sobre la validez (o, por supuesto también, sobre la interpretación) del Derecho comunitario ${ }^{35}$.

8. Profundizando en la motivación que lleva al abogado laboralista a sembrar en el juez la duda sobre la aplicabilidad al caso del Derecho comunitario, pensamos que dicho abogado se encontrará usualmente con un pleito perdido — si es que se aplicasen al mismo únicamente parámetros de Derecho nacional (contenidos, por ejemplo, en una Ley)_, de donde que pretenda invertir ese pronóstico adverso para su cliente, mediante el injerto de parámetros enjuiciadores de Derecho de la Unión Europea (por ejemplo, una Directiva), ya en el propio escrito de demanda. Creemos que ejemplifica a la perfección todo esto, dentro de la casuística judicial laboral que manejamos, el supuesto de hecho enjuiciado por una Sentencia de la Sala de lo Social del Tribunal Supremo de 17 septiembre 2014, fallada en casación ordinaria ${ }^{36}$, donde se relata que el abogado de la parte demandante solicitaba, precisamente en la propia demanda de conflicto colectivo, de un lado - a título de pretensión previa principal-, que «con suspensión provisional de las actuaciones, se formule por parte de esa Sala [de lo Social de la Audiencia Nacional] la cuestión prejudicial ante el Tribunal de Justicia de las Comunidades Europeas, de acuerdo con lo previsto en el art. 267 del Tratado de Funcionamiento de la Unión Europea, sobre la inaplicación de una norma interna que no ha contado con la solicitud de dictamen previo ante el Banco Central Europeo» ${ }^{37}$; y de otro lado - a título de pretensión previa subsidiaria-, también que «con suspensión provisional de las actuaciones hasta que el Tribunal Constitucional se pronuncie sobre su admisión, se formule por el Tribunal de instancia cuestión de inconstitucionalidad del RD-Ley 20/2012 ${ }^{38}$. Por supuesto, nada cabe objetar a la priorización de la cuestión prejudicial europea sobre la cuestión de inconstitucionalidad efectuada por el abogado en cuestión, pues la primera — según las estadísticas oficiales del Tribunal de Luxemburgo - podría resolverse en poco más de un año y medio (más exactamente, una media de «18,7» meses en 2016) ${ }^{39}$, mientras que la tramitación de la segunda está sujeta no sólo a un «incertus an», sino también - y sobre todo- a un evidente «incertus quando».

9. Creemos que también juega a favor de esa priorización el hecho de que exista una importante diferencia, de carácter normativo-formal, entre la cuestión prejudicial

\footnotetext{
${ }^{32}$ Serie C 338/1, de 6 noviembre 2012.

${ }^{33}$ Cfr. Apartado I, marginal 12.

${ }^{34}$ Cfr. Apartado I, marginal 17.

${ }^{35}$ Cfr. Apartado I, marginal 16.

${ }^{36}$ Citada supra, núm. 3.

${ }^{37} \mathrm{Cfr}$. Antecedente de Hecho primero.

38 Ibidem.

${ }^{39}$ Véase Court of Justice of the European Union. Annual report 2016. Judicial activity, cit., pág. 213.
} 
europea y la cuestión de inconstitucionalidad ${ }^{40}$. En efecto, por ningún lado se afirma en la Ley orgánica 2/1979, de 3 octubre, del Tribunal Constitucional- que el juez ordinario tenga el «deber» de plantear cuestión de inconstitucionalidad, mientras que el artículo 267 del Tratado de Funcionamiento de la Unión Europea sí afirma expresamente, por el contrario, que dicha obligación puede llegar a existir (literalmente, «Cuando se plantee una cuestión de este tipo en un asunto pendiente ante un órgano jurisdiccional, cuyas decisiones no sean susceptibles de ulterior recurso judicial de Derecho interno, dicho órgano estará obligado a someter la cuestión al Tribunal») ${ }^{41}$, pareciéndonos claro a nosotros - respecto de la secuencia litigiosa más frecuente, y a pesar de que el Tribunal Constitucional cometiese la imprudencia de plantear, en 2011, una solitaria cuestión prejudicial al Tribunal de Luxemburgo, verdadero «unicum» ${ }^{42}$ que el «órgano jurisdiccional» a que alude dicho precepto del Tratado no es el Tribunal Constitucional, sino la Sala de lo Social del Tribunal Supremo. Por lo demás, las citadas «Recomendaciones a los órganos jurisdiccionales nacionales, relativas al planteamiento de cuestiones prejudiciales», mencionan algún supuesto más en que el órgano jurisdiccional nacional, cualquiera que fuese (por ejemplo, un Juzgado de lo Social, aunque sobre el asunto pudiese caber luego la interposición de recurso de suplicación), tendría el deber de plantear inmediatamente cuestión prejudicial (literalmente, «todo órgano jurisdiccional nacional debe [sic; en negrita, en el original] remitir una petición de decisión prejudicial al Tribunal de Justicia cuando albergue dudas sobre la validez [no sobre la interpretación] de tal acto [esto es, "un acto de una institución, de un órgano o de un organismo de la Unión"], indicando los motivos por los que considera que dicho acto podría no ser válido») ${ }^{43}$.

\section{LA POSICIÓN DEL ABOGADO LABORALISTA DEL DEMANDADO}

10. Pensando siempre en el supuesto de hecho más frecuente en los procesos laborales, la regla general es que el demandado sea una empresa o el $\mathrm{INSS}^{44}$, defendidos por el típico abogado «de empresas» o por el que la doctrina científica denomina «ejército de abogados-funcionarios» al servicio de la Administración de Seguridad Social ${ }^{45}$, respectivamente. Tendría a mano una panoplia de defensas procesales y materiales, orientadas a destruir o enervar el intento del demandante de crear la convicción de que el juez laboral debería plantear la cuestión prejudicial europea (alimentando, de paso, el

\footnotetext{
${ }^{40}$ Sobre el tema, véase R. ALONSO GARCÍA, El Juez Nacional en la Encrucijada Europea de los Derechos Fundamentales, Thomson Reuters Civitas (Cizur Menor, 2014), págs. 125 y ss.

${ }^{41}$ Párrafo tercero.

${ }^{42}$ Véase Auto 86/2011, de 9 junio, del Pleno del Tribunal Constitucional, por el que se acuerda el planteamiento de cuestión prejudicial al Tribunal de Justicia de la Unión Europea y suspensión de la tramitación del recurso de amparo 6922-2008, a propósito de un asunto penal. Analizándolo, véase J.M MACÍAS CASTAÑO, La cuestión prejudicial europea y el Tribunal Constitucional. El asunto Melloni, Atelier (Barcelona, 2014), págs. 123 y ss.

${ }^{43}$ Cfr. apartado I, marginal 16. Más sobre el tema, en J. HUELIN MARTÍNEZ DE VELASCO, «La cuestión prejudicial europea. Facultad/obligación de plantearla», en R. ALONSO GARCÍA y J.I. UGARTEMENDIA ECEIZABARRENA (Directores), La cuestión prejudicial europea, cit., págs. 44 y ss.

${ }^{44} \mathrm{Al}$ respecto, véase J. MARTÍNEZ GIRÓN y A. ARUFE VARELA, Derecho crítico del Trabajo. Critical Labor Law, $4^{\mathrm{a}}$ ed., cit., págs. 254-255.

${ }^{45}$ Véase M. SILVEIRO DE BARROS, Los honorarios de abogados en procesos de seguridad social. Un estudio comparado de los ordenamientos norteamericano, español y portugués, Atelier (Barcelona, 2017), pág. 107.
} 
ya comentado escepticismo judicial en este tema), y sobre las cuales viene pronunciándose la jurisprudencia laboral por libre, al no existir aquí ningún apoyo normativo rotundo o claro. Es el caso, por ejemplo, de la defensa procesal de «cuestión nueva» - supuesto que se aduzca, por parte del impugnante de un recurso, que «se ha planteado una cuestión nueva por los recurrentes, al interesar que por este Tribunal se interponga una cuestión prejudicial ante el TJUE» ${ }^{46}$-, respecto de la que una Sentencia de la Sala de lo Social del Tribunal Supremo de 16 septiembre 2014, fallada en casación $\operatorname{ordinaria}^{47}$, de un lado, afirma que «la alegación de ilegalidad comunitaria que se ha hecho en el recurso no fue así formulada en la instancia y, si tenemos en cuenta que el recurso de casación es un recurso extraordinario, no puede considerarse congruente con el derecho constitucional del art. 24 de la Constitución el que se alegue en este trámite casacional un argumento que no fue esgrimido en una anterior fase procesal, de acuerdo con la propia naturaleza de este recurso lo que se traduce en que la tradicional doctrina de la Sala haya dicho de forma reiterada que no pueden alegarse cuestiones nuevas constitutivas de un "novum iudicium" en trámite de casación por la indefensión que pueden producir en la contraparte» ${ }^{48}$; y de otro lado, matiza —eso sí, tras afear la actuación del recurrente- que «si partimos de la base de que la parte que lo pide lo ha hecho a destiempo y por ello formalmente no es una petición vinculante para el Tribunal, también es cierto que éste - esta Sala - podría y debería plantearla [la cuestión prejudicial europea] si tuviera la más mínima duda de que la norma nacional viola el derecho comunitario; pero nada de esto puede apreciarse en el presente caso» ${ }^{49}$.

11. Otra posible defensa podría ser la de cosa juzgada, a la que contundentemente se refiere una Sentencia de la Sala de lo Social del Tribunal Superior de Justicia de la Comunidad Valenciana de 15 junio $1993^{50}$. En este caso, lo que solicitaban «los actores recurrentes» en suplicación era «la anulación de actuaciones ... pues ... [el recurso] argumenta [que] en las demandas se articuló al amparo del art. 177 del Tratado de la Comunidad Económica Europea cuestión prejudicial a fin de que el Tribunal de Justicia de las Comunidades Europeas se pronunciase sobre la aplicabilidad directa a España del art. 3.1 de la Directiva 77/1987, de 14-2-1977 sobre los derechos y obligaciones que resulten para el cedente de un contrato de trabajo, [y] ello obligaba, concluye, a que dicha cuestión debió ser resuelta en la sentencia, y al no hacerlo, [esto obliga, a su vez, a] reponer las actuaciones al momento anterior a dictar sentencia para que se decidiese sobre ello» ${ }^{51}$. Ahora bien, frente a este alegato, la Sala de suplicación concluyó que dicho motivo «no puede prosperar», razonando todo lo siguiente: «En autos consta que tal petición fue rechazada por Providencia de 10-9-1991 y que contra tal acuerdo no se recurrió ni formuló protesta alguna. Como tampoco se hizo a lo largo del procedimiento. Ello hace que dicha denegación causase estado, por lo que, sin necesidad de cualquiera otra argumentación, cabe concluir que fue expresamente resuelta dicha petición y no puede ahora hacerse renacer cuando tan patentemente se consintió su rechazo» ${ }^{52}$.

\footnotetext{
${ }^{46}$ Sobre dicho concreto motivo de impugnación, véase Sentencia de la Sala de lo Social del Tribunal Supremo de 16 septiembre 2014, fallada en casación ordinaria (citada supra, núm. 3), Fundamento de Derecho quinto, párrafo penúltimo.

${ }^{47}$ Citada supra, núm. 3.

${ }^{48}$ Cfr. Fundamento de Derecho tercero, apartado 3, párrafo primero.

49 Ibidem, párrafo segundo.

${ }^{50}$ Citada supra, núm. 3.

${ }^{51}$ Cfr. Fundamento de Derecho primero.

${ }^{52}$ Ibidem.
} 
12. En fin, la defensa de fondo más contundente está representada, sin duda, por la invocación de la doctrina del «acto claro», sobre la que monográficamente se pronuncia - con discordia judicial — una Sentencia de la Sala de lo Social del Tribunal Supremo (constituida en Sala General) de 24 junio 2009, fallada en casación para la unificación de doctrina ${ }^{53}$. Cuenta con un voto particular redactado por el Magistrado y Catedrático Sr. Antonio MARTÍN VALVERDE (al que se adhirieron el Presidente de la Sala, Sr. Gonzalo MOLINER TAMBORERO, la Magistrada Sra. Milagros CALVO IBARLUCEA, y los Magistrados Sres. Aurelio DESDENTADO BONETE y Jesús SOUTO PRIETO), en el que lo único que se defiende es que «esta Sala de lo Social del Tribunal Supremo ha debido plantear una cuestión prejudicial al Tribunal de Justicia de la Comunidad Europea (TJCE) sobre la interpretación del Derecho Comunitario en la materia controvertida ${ }^{54}$. Frente a esta opinión, sin embargo, la mayoría de la Sala con ponencia a cargo del Magistrado Sr. Luis Fernando DE CASTRO FERNÁNDEZdecidió no plantearla, razonando a este efecto lo siguiente: 1) «los órganos judiciales no están obligados a plantear cuestión prejudicial cuando la respuesta a ella pueda deducirse con seguridad — sin duda razonable — de la jurisprudencia comunitaria ya dictada; es lo que se denomina doctrina del "acto claro"»" 55 ; 2 «la Sala no desconoce, ciertamente, el rigor exigido por el Tribunal de Justicia para la apreciación del "acto claro"», pues «para ello "el órgano jurisdiccional nacional debe llegar a la convicción de que la misma evidencia se impondría a los órganos jurisdiccionales nacionales de los otros Estados miembros, así como al Tribunal de Justicia" y que "tan sólo si estas condiciones se reúnen puede abstenerse el órgano jurisdiccional nacional de someter la cuestión al Tribunal de Justicia y resolver bajo su propia responsabilidad"»" ${ }^{56}$; y 3) admitiendo que la claridad o «certidumbre» del Derecho nunca puede serlo al cien por cien, concluyó que «estas rigurosas exigencias no imponen en el presente caso - pese a todo- el planteamiento de la cuestión prejudicial, por cuanto que en manera alguna afirmamos — ni consideramos "acto claro" - que la doctrina sentada por la STJCE [cuya doctrina se debatía] sea directamente aplicable al caso objeto de debate» ${ }^{57}$.

\section{EPÍLOGO}

13. En nuestra opinión, es evidente — por todo lo dicho- que la regulación normativa en nuestro Derecho interno del tema de la cuestión prejudicial europea resulta clamorosamente insuficiente. De ahí, mientras no vuelva a enmendarse la Ley orgánica de poder judicial, que el legislador español fuerce a nuestros tribunales, incluidos los tribunales laborales, a tener que moverse en tierra de nadie e, incluso, a tener que actuar - por qué no decirlo - flagrantemente al margen de la ley. En este sentido, habría que poner claridad no sólo en los temas citados del contenido de las pretensiones, de las defensas frente a ellas y de la discrecionalidad o no del tribunal nacional al enjuiciar unas y otras, sino también en el de una eventual (y prudente) suspensión de las actuaciones judiciales, mientras se encuentre en tramitación — sobre un asunto idéntico o análogo - una cuestión prejudicial europea previamente planteada. Este último problema lo detectó ya, hace ahora veinte años, una Sentencia de la Sala de lo Social del

\footnotetext{
${ }^{53}$ Citada supra, núm. 3.

${ }^{54}$ Cfr. Fundamento de Derecho primero, párrafo segundo.

${ }^{55}$ Cfr. Fundamento de Derecho quinto, apartado 2.

${ }^{56}$ Ibidem, apartado 3.

${ }^{57}$ Ibidem, apartado 4.
} 
Tribunal Supremo de 12 febrero 1997, fallada en casación para la unificación de doctrina $^{58}$. En ella, frente al dilema de tener que volver a plantear cuestión prejudicial, o de tener que prescindir de la suerte de la cuestión prejudicial en curso o, por último, de tener que proceder a suspender la tramitación del proceso laboral análogo asimismo en curso, optó por esta tercera alternativa, razonando — sin amparo legal ninguno, y por razones de mera conveniencia - todo lo que sigue: «La petición alternativa deducida en el tema previo, de suspensión o demora del procedimiento del presente recurso, era atendible y ha sido finalmente atendida en el trámite del asunto. Aunque esta Sala no tuviera dudas sobre la decisión del litigio, es cierto que los enunciados normativos de Derecho comunitario aplicables al caso tienen una considerable complejidad. Siendo ello así, en la circunstancia de cuestión prejudicial pendiente, era aconsejable la pausa solicitada en la tramitación hasta que culminara el procedimiento de colaboración interjurisdiccional previsto en el art. 177 del Tratado de Roma [hoy artículo 267 del Tratado de Funcionamiento de la Unión Europea]» ${ }^{59}$.

\section{BIBLIOGRAFÍA}

ALONSO GARCÍA, R., El Juez Nacional en la Encrucijada Europea de los Derechos Fundamentales, Thomson Reuters Civitas (Cizur Menor, 2014).

ALONSO GARCÍA, R., «La cuestión prejudicial, piedra angular de la integración europea», en R. ALONSO GARCÍA y J.I. UGARTEMENDIA ECEIZABARRENA (Directores), La cuestión prejudicial europea, IVAP (Oñati, 2014).

ARUFE VARELA, A., El Derecho de la Seguridad Social en la jurisprudencia de la Corte Suprema de los Estados Unidos. Un estudio de veintisiete grandes casos, desde la perspectiva del Derecho español, Atelier (Barcelona, 2014).

HUELIN MARTÍNEZ DE VELASCO, J., «La cuestión prejudicial europea. Facultad/obligación de plantearla», en R. ALONSO GARCÍA y J.I. UGARTEMENDIA ECEIZABARRENA (Directores), La cuestión prejudicial europea, IVAP (Oñati, 2014).

MARTÍNEZ GIRÓN, J., Quince grandes casos de la Corte Suprema de los Estados Unidos sobre Derecho individual del Trabajo. Un estudio desde la perspectiva del Derecho español, Netbiblo (A Coruña, 2012).

MARTÍNEZ GIRÓN, J. y ARUFE VARELA, A., Derecho crítico del Trabajo. Critical Labor Law, $4^{\mathrm{a}}$ ed., Atelier (Barcelona, 2016).

MARTÍNEZ GIRÓN, J., ARUFE VARELA, A. y CARRIL VÁZQUEZ, X.M., Derecho del Trabajo, $2^{\mathrm{a}}$ ed., Netbiblo (A Coruña, 2006).

MARTÍNEZ GIRÓN, J., ARUFE VARELA, A. y CARRIL VÁZQUEZ, X.M., Derecho de la Seguridad Social, $4^{\text {a }}$ ed., Atelier (Barcelona, 2017).

\footnotetext{
${ }^{58}$ Citada supra, núm. 3.

${ }^{59}$ Fundamento de Derecho segundo, párrafo segundo.
} 
SILVEIRO DE BARROS, M., Los honorarios de abogados en procesos de seguridad social. Un estudio comparado de los ordenamientos norteamericano, español y portugués, Atelier (Barcelona, 2017). 